\title{
Heparin versus bivalirudin for percutaneous coronary intervention: has the debate come to an end?
}

\author{
Islam Y. Elgendy ${ }^{1}$, Davide Capodanno ${ }^{2}$ \\ ${ }^{1}$ Division of Cardiovascular Medicine, Department of Medicine, University of Florida, Gainesville, FL, USA; ${ }^{2}$ Division of Cardiology, Ferrarotto \\ Hospital, University of Catania, Catania, Italy \\ Correspondence to: Islam Y. Elgendy, MD. Division of Cardiovascular Medicine, Department of Medicine, University of Florida, 1600 SW Archer \\ Road, PO Box 100277, Gainesville, FL 32610, USA. Email: iyelgendy@gmail.com. \\ Provenance: This is an invited Editorial commissioned by the Section Editor Hai-Long Dai (Department of Cardiology, Yan'an Affiliated Hospital of \\ Kunming Medical University, Kunming, China). \\ Comment on: Erlinge D, Omerovic E, Fröbert O, et al. Bivalirudin versus Heparin Monotherapy in Myocardial Infarction. N Engl J Med \\ 2017;377:1132-42.
}

Submitted Oct 05, 2017. Accepted for publication Oct 09, 2017.

doi: $10.21037 /$ jtd.2017.10.23

View this article at: http://dx.doi.org/10.21037/jtd.2017.10.23

Percutaneous coronary intervention (PCI) is the cornerstone of management for patients with ST-elevation myocardial infarction (STEMI) and non-ST-elevation myocardial infarction (NSTEMI) (1-6). Anticoagulation is routinely administered during PCI in order to minimize the risk of thrombotic events. However, the choice of anticoagulation should be balanced with the risk of bleeding. For years, unfractionated heparin was the standard anticoagulant strategy for PCI. The addition of intravenous glycoprotein $\mathrm{IIb} / \mathrm{III}$ receptor inhibitors to unfractionated heparin led to a reduction in the risk of thrombotic events, such as stent thrombosis and myocardial infarction but this approach was associated with increased bleeding (7). With the introduction of $\mathrm{P}_{2} \mathrm{Y}_{12}$ antagonists, we have learned that the routine use of intravenous glycoprotein IIb/IIIa receptor inhibitors does not improve clinical outcomes and only increases the risk of bleeding (8), thus the use of intravenous glycoprotein IIb/ IIIa receptor inhibitors has been limited to a bail-out, rather than a routine strategy, in combination with unfractionated heparin.

Over the past two decades, bivalirudin, a direct thrombin inhibitor, has been introduced as an alternative to unfractionated heparin. Early randomized trials comparing both anticoagulants for STEMI and NSTEMI have consistently shown that bivalirudin had a similar risk of composite ischemic events as compared with unfractionated heparin plus routine intravenous glycoprotein IIb/IIIa receptor inhibitors, with the advantage of a lower bleeding risk (9-12). The lower risk of bleeding that was observed with bivalirudin in these trials was partly attributed to the unbalanced use of intravenous glycoprotein IIb/IIIa receptor inhibitors in both arms (13-15). In the recent years, two advances of PCI have added further to this debate. First, the introduction of more potent and rapidly acting $\mathrm{P} 2 \mathrm{Y}_{12}$ antagonists (i.e., prasugrel, ticagrelor, and cangrelor) which are associated with lower risk of ischemic complications compared with clopidogrel. Second, the more frequent use of a radial access for PCI, which is associated with lower bleeding risk as compared with femoral access (16). Randomized trials conducted in this era of potent $\mathrm{P} 2 \mathrm{Y}_{12}$ antagonists with a more prevalent use of radial access have shown no difference in the risk of composite ischemic events, albeit that the risk of stent thrombosis (particularly acute stent thrombosis) was consistently higher with bivalirudin, but these trials have yielded inconsistent results as regards to the bleeding benefit which was previously noted with bivalirudin (17-20). In a meta-analysis of randomized trials comparing both agents for patients undergoing PCI via radial access, bivalirudin was not associated with a lower risk of bleeding compared with unfractionated heparin (21). With these uncertainties and the remarkably higher cost of bivalirudin, a contemporary trial comparing both bivalirudin versus unfractionated heparin alone for radial PCI in patients exclusively treated with potent $\mathrm{P} 2 \mathrm{Y}_{12}$ antagonists would be 
helpful to address these ambiguities.

In this context, the VALIDATE-SWEDEHEART (Bivalirudin versus Heparin in ST-Segment and Non-STSegment Elevation Myocardial Infarction in Patients on Modern Antiplatelet Therapy in the Swedish Web System for Enhancement and Development of Evidence-based Care in Heart Disease Evaluated According to Recommended Therapies Tegistry Trial) compared bivalirudin versus unfractionated heparin alone in 6,006 patients undergoing PCI for STEMI and NSTEMI in Sweden (22). PCI was performed via radial approach in $\sim 90 \%$ of the cases. Ticagrelor was administered in $\sim 95 \%$ of the subjects, prasugrel in $\sim 2 \%$, and cangrelor in $0.3 \%$. Bail-out intravenous glycoprotein IIb/IIIa receptor inhibitors were given only in $2.4 \%$ in the bivalirudin arm and $2.8 \%$ in the unfractionated heparin arm. At 180-day, there was no difference between both groups in the primary outcome, which was the composite of death from any cause, myocardial infarction, or major bleeding $[12.3 \%$ vs. $12.8 \%$; hazard ratio (HR): 0.96; 95\% confidence interval (CI), 0.83-1.10; $\mathrm{P}=0.54)]$. There was no difference in the rate of major bleeding between both agents (HR: 1.00; 95\% CI, 0.84-1.19, $\mathrm{P}=0.98)$. In addition, the rate of definite stent thrombosis was not statistically higher with bivalirudin (HR: 0.54; 95\% CI, $0.27-1.10, \mathrm{P}=0.09)$. The results were consistent in those with STEMI versus NSTEMI.

The VALIDATE-SWEDEHEART represents the most contemporary trial comparing both agents and showed no difference between bivalirudin and unfractionated heparin alone for PCI for STEMI and NSTEMI. In contrast to most of the previous trials, the rate of major bleeding was not reduced with bivalirudin in this study. The frequent use of radial access for PCI, and the minimal use of intravenous glycoprotein IIb/IIIa receptor inhibitors could help to explain this finding. Interestingly, the risk of definite stent thrombosis was not statistically increased with bivalirudin, which could be attributed to the use of potent $\mathrm{P} 2 \mathrm{Y}_{12}$ antagonists. In addition, $\sim 65 \%$ of patients in the bivalirudin arm were treated with prolonged bivalirudin infusion, which has been suggested as a strategy to mitigate stent thrombosis with bivalirudin (23). Data regarding acute stent thrombosis, which has been the main derivative for the increased risk of stent thrombosis in the previous trials, are lacking in this study. Despite the criticism that might arise from the lower than anticipated event rates $(\sim 12.8 \%$ in the unfractionated heparin arm as opposed to the anticipated rate of $15.8 \%$ ), this trial was well conducted and provided answers to some questions regarding anticoagulation choice for contemporary PCI for patients with MI. While the trial was not sufficiently powered to determine differences for the individual end points, the event rates for the individual end points were almost similar in both arms.

In summary, the findings of the VALIDATESWEDEHEART suggest that bivalirudin might not confer any advantage over unfractionated heparin alone for contemporary PCI for myocardial infarction (i.e., via radial access, and a bail-out strategy for intravenous glycoprotein IIb/IIIa receptor inhibitors, with potent $\mathrm{P} 2 \mathrm{Y}_{12}$ antagonists). With the significantly higher cost of bivalirudin, compared with unfractionated heparin, there might not a significant role for bivalirudin in the catheterization laboratory except for those with history of heparin-induced thrombocytopenia and in obese individuals who are undergoing PCI via a femoral approach. The VALIDATE-SWEDEHEART appears to have put an end to the ongoing debate for the past two decades to determine the optimum anticoagulant for PCI for patients with myocardial infarction, and suggests that the old, cheap unfractionated heparin might be sufficient for PCI for most if not all patients with STEMI and NSTEMI.

\section{Acknowledgements}

None.

\section{Footnote}

Conflicts of Interest: The authors have no conflicts of interest to declare.

\section{References}

1. American College of Emergency Physicians; Society for Cardiovascular Angiography and Interventions, O'Gara PT, et al. 2013 ACCF/AHA guideline for the management of ST-elevation myocardial infarction: a report of the American College of Cardiology Foundation/American Heart Association Task Force on Practice Guidelines. J Am Coll Cardiol 2013;61:e78-140.

2. Ibanez B, James S, Agewall S, et al. 2017 ESC Guidelines for the management of acute myocardial infarction in patients presenting with ST-segment elevation: The Task Force for the management of acute myocardial infarction in patients presenting with ST-segment elevation of the European Society of Cardiology (ESC). Eur Heart J 2017. [Epub ahead of print]. 
3. Amsterdam EA, Wenger NK, Brindis RG, et al. 2014 AHA/ACC Guideline for the Management of Patients with Non-ST-Elevation Acute Coronary Syndromes: a report of the American College of Cardiology/American Heart Association Task Force on Practice Guidelines. J Am Coll Cardiol 2014;64:e139-228.

4. Roffi M, Patrono C, Collet JP, et al. 2015 ESC Guidelines for the management of acute coronary syndromes in patients presenting without persistent ST-segment elevation: Task Force for the Management of Acute Coronary Syndromes in Patients Presenting without Persistent ST-Segment Elevation of the European Society of Cardiology (ESC). Eur Heart J 2016;37:267-315.

5. Elgendy IY, Kumbhani DJ, Mahmoud AN, et al. Routine invasive versus selective invasive strategies for Non-STelevation acute coronary syndromes: An Updated metaanalysis of randomized trials. Catheter Cardiovasc Interv 2016;88:765-74.

6. Elgendy IY, Mahmoud AN, Mansoor H, et al. Early invasive versus initial conservative strategies for women with non-ST-elevation acute coronary syndromes: A nationwide analysis. Am J Med 2017;130:1059-67.

7. De Luca G, Suryapranata H, Stone GW, et al. Abciximab as adjunctive therapy to reperfusion in acute ST-segment elevation myocardial infarction: A meta-analysis of randomized trials. JAMA 2005;293:1759-65.

8. Le May MR, Wells GA, Glover CA, et al. Primary percutaneous coronary angioplasty with and without eptifibatide in ST-segment elevation myocardial infarction: a safety and efficacy study of integrilin-facilitated versus primary percutaneous coronary intervention in STsegment elevation myocardial infarction (ASSIST). Circ Cardiovasc Interv 2009;2:330-8.

9. Stone GW, McLaurin BT, Cox DA, et al. Bivalirudin for patients with acute coronary syndromes. N Engl J Med 2006;355:2203-16.

10. Stone GW, Witzenbichler B, Guagliumi G, et al. Bivalirudin during primary PCI in acute myocardial infarction. N Engl J Med 2008;358:2218-30.

11. Kastrati A, Neumann FJ, Schulz S, et al. Abciximab and heparin versus bivalirudin for non-ST-elevation myocardial infarction. N Engl J Med 2011;365:1980-9.

12. Capodanno D, Gargiulo G, Capranzano P, et al. Bivalirudin versus heparin with or without glycoprotein $\mathrm{IIb} / \mathrm{III} \mathrm{a}$ inhibitors in patients with STEMI undergoing primary PCI: An updated meta-analysis of 10,350 patients from five randomized clinical trials. Eur Heart J Acute
Cardiovasc Care 2016;5:253-62.

13. Cavender MA, Sabatine MS. Bivalirudin versus heparin in patients planned for percutaneous coronary intervention: a meta-analysis of randomised controlled trials. Lancet 2014;384:599-606.

14. Mahmoud A, Saad M, Elgendy AY, et al. Bivalirudin in percutaneous coronary intervention, is it the anticoagulant of choice? Cardiovasc Ther 2015;33:227-35.

15. Bavry AA, Elgendy IY, Mahmoud A, et al. Critical appraisal of bivalirudin versus heparin for percutaneous coronary intervention: A meta-analysis of randomized trials. PLoS One 2015;10:e0127832.

16. Valgimigli M, Gagnor A, Calabró $P$, et al. Radial versus femoral access in patients with acute coronary syndromes undergoing invasive management: a randomised multicentre trial. Lancet 2015;385:2465-76.

17. Steg PG, van't Hof A, Hamm CW, et al. Bivalirudin started during emergency transport for primary PCI. N Engl J Med 2013;369:2207-17.

18. Han Y, Guo J, Zheng Y, et al. Bivalirudin vs heparin with or without tirofiban during primary percutaneous coronary intervention in acute myocardial infarction: the BRIGHT randomized clinical trial. JAMA 2015;313:1336-46.

19. Shahzad A, Kemp I, Mars C, et al. Unfractionated heparin versus bivalirudin in primary percutaneous coronary intervention (HEAT-PPCI): an open-label, single centre, randomised controlled trial. Lancet 2014;384:1849-58.

20. Valgimigli M, Frigoli E, Leonardi S, et al. Bivalirudin or unfractionated heparin in acute coronary syndromes. N Engl J Med 2015;373:997-1009.

21. Mahmoud AN, Elgendy IY. Bivalirudin versus unfractionated heparin for percutaneous coronary intervention with radial access: A meta-analysis of randomized trials. Int J Cardiol 2016;216:128-32.

22. Erlinge D, Omerovic E, Fröbert O, et al. Bivalirudin versus heparin monotherapy in myocardial infarction. $\mathrm{N}$ Engl J Med 2017;377:1132-42.

23. Shah R, Rogers KC, Ahmed AJ, et al. Effect of post-primary percutaneous coronary intervention bivalirudin infusion on acute stent thrombosis: meta-analysis of randomized controlled trials. JACC Cardiovasc Interv 2016;9:1313-20.

Cite this article as: Elgendy IY, Capodanno D. Heparin versus bivalirudin for percutaneous coronary intervention: has the debate come to an end? J Thorac Dis 2017;9(11):4305-4307. doi: $10.21037 /$ jtd.2017.10.23 